\title{
SIMULATION OF NEW HEALTHCARE DELIVERY TO EVALUATE IMPACTS ON PATIENT ACCESS TO CARE: A TELEHEALTH SUPPLY AND DEMAND USE CASE
}

\author{
Matthew Henchey, PhD \\ Modeling, Simulation, Experimentation and Analytics \\ The MITRE Corporation \\ 7515 Colshire Drive \\ McLean, VA USA \\ mhenchey@mitre.org
}

Deborah Ercolini, MS

Data and Human Centered Solutions

The MITRE Corporation

202 Burlington Road

Bedford, MA USA

deb@mitre.org

\author{
Sybil Klaus, MD, MPH \\ Health Transformation \\ The MITRE Corporation \\ 7515 Colshire Drive \\ McLean VA USA \\ sklaus@mitre.org
}

\begin{abstract}
We propose a framework, Modeling HealthCARE: Capacity, Access, and Resource Evaluation, that uses hybrid simulation to help healthcare organizations evaluate supply and demand as they implement alternative healthcare services. The focus of this tool is on patients and their access to care. We integrate agent-based and discrete event simulation to model the patient as an agent adopting and requesting new services, following a discrete-event-driven process based on the existing and new healthcare journey. We model a use case in which a regional Department of Veterans Affairs healthcare organization is expanding its telehealth capabilities to meet growing demand for Post-Traumatic Stress Disorder treatment and is using telehealth to deliver services to Veterans, which saves them from traveling long distances. Results of our proof of concept model show that as adoption of telehealth increases, wait times and travel distances decrease, as service capacity and resources are configured to meet demand.
\end{abstract}

Keywords: healthcare, access to care, supply and demand, telehealth

\section{INTRODUCTION}

As healthcare organizations are looking at how best to implement new healthcare delivery services, decision makers need a way to evaluate the supply and demand for those services and the impacts changes would have on patients' access to care. One example of an expanding healthcare service is telehealth and virtual care. The Department of Veterans Affairs (VA) is using telehealth technologies to make it easier for Veterans to connect with specialists around the county (U.S. Dept. of Veterans Affairs 2019). Our first use case focuses on VA's expansion of telehealth. However, it is important to note that this research was conducted independently from VA using publicly available and synthetic data.

This research creates a framework, Modeling HealthCARE: Capacity, Access, and Resource Evaluation, to aid resource planning and inform decision makers of regional healthcare systems about the impacts of healthcare changes. This work includes researching and developing hybrid simulations to model healthcare, focusing on the integration of telehealth services to help healthcare systems understand supply and demand requirements, understanding the impact of implementing new telehealth services, and making data-driven decisions to provide patient-centric care. 
The initial use case is the Veterans Health Administration (VHA) within South Carolina (SC), and the treatment of Veteran patients diagnosed with Post Traumatic Stress Disorder (PTSD). The hypothesis is that modeling use cases and scenarios will help to identify key problems that the VHA and other organizations repeatedly must resolve to integrate telehealth in a way that is truly adaptive to the patient's circumstances. This includes education, health literacy, level of comfort with technology, preferences for interaction, and clinical need. This hybrid approach integrates agent-based and discrete event simulation to model the patient as an agent adopting and requesting the new service, which follows a discrete-event driven process based on the existing and new healthcare journey.

These models identify gaps in personnel, resources, technology, and policies that will inform further research opportunities in telehealth and mobile healthcare. They also provide a framework for evaluating options in a simulated environment, allowing healthcare systems to make informed investment decisions around future delivery of telehealth services without having to go through costly physical pilots. As research continues, these models may be extended to provide a platform for assessing multiple services across the various healthcare systems, which can help the systems to maximize access to care and quality of care.

\section{RECENT RELATED RESEARCH}

Agent-based and discrete event simulation and systems dynamics models are not new to the healthcare domain, and have been used in the past to:

- Model patients and providers as agents to evaluate the impact on cost and quality of patient choice in accountable care organizations (Alibrahim and $\mathrm{Wu} 2018$ );

- Develop a decision support system for emergency department operations using agent-based simulation and data mining techniques to allow 'what-if' scenario evaluation (Saoud, Boubetra and Attia 2018);

- Evaluate different models of emergency department considering flow models and physical design, measuring patient-centric metrics such as length of stay and door to provider time (Easter, et al. 2019);

- Combine agent-based simulation and business process modeling to analyze healthcare processes and available resources in an emergency department (Sbayou, et al. 2017);

- Explore policies using a system dynamics model to help alleviate the rural healthcare gap, such as financial and educational incentives offered to rural providers (Sian Morgan and Graber-Naidich 2019);

- Model operations within Johns Hopkins Medicine's command center in order to test out changes and evaluate impacts to the hospital (Roth 2018); and

- Simulate regional food supply chain management strategies and producer decisions (Craven and Krejci 2017).

Many hospital and emergency department simulation models focus on the supply and demand of daily operations that account for factors like arrival rates, emergency severity, and resources available to evaluate metrics such as length of stay and time to see a provider. Simulations that model policy decisions around patient choice and the use of incentives to attract providers to rural areas, or even food supply chain management strategies that consider producer behaviors and decisions, are focused on more long-term and strategic outcomes. A recent review of hybrid simulation modeling highlights how approaches that combine two or more of these methods "has experienced near-exponential growth" over the past twenty years, with $22 \%$ of the 139 papers they reviewed being applied to the healthcare domain (Brailsford, et al. 2019). Hybrid simulation offers an opportunity to bring these two levels of modeling together to consider the supply and demand of healthcare resources, the behaviors and decisions of patients, and the rollout of new healthcare delivery options to improve patient access to care and understand the impacts to patient-centric measures. 
For our initial use case, incorporation of telehealth into PTSD treatment delivery requires all of these to be considered as the VHA healthcare system stretches across the US and its supply and demand is not a localized problem. Using agent-based and discrete-event simulation together in a hybrid model allows us to simulate individual patient behaviors and choices, their journey through the healthcare system, the healthcare delivery paths, and the capacity and resource settings. We can then evaluate impacts to supply, demand, and patient-centric metrics.

\section{MODELING HEALTHCARE FRAMEWORK}

Using a systems engineering approach, Modeling HealthCARE is a five-step framework that is intended to help healthcare organizations evaluate and make data-driven decisions about proposed changes to their offerings with respect to technology, resources, and policies. This framework presents a holistic and integrated model that can help to improve the patient experience and access to timely care. This considers a patient's individual circumstances, level of comfort with technology, preferences for interaction, health literacy, and clinical need.

In the sections which follow, we will explain each step as well as describe in detail how this framework is used to address a specific use case: Telehealth for PTSD Treatment. This use case investigates the impact of augmenting traditional services with telehealth capabilities to provide PTSD treatment within South Carolina. Figure 1 provides an overview of the five steps of this framework. At any step within the framework, it is possible and may be necessary to go back to the beginning to adjust the hypothesis and objective, revise the patient journey map, gather and analyze additional data, refine the modeling and simulation $(M \& S)$ environment, and identify new questions that need to be answered.

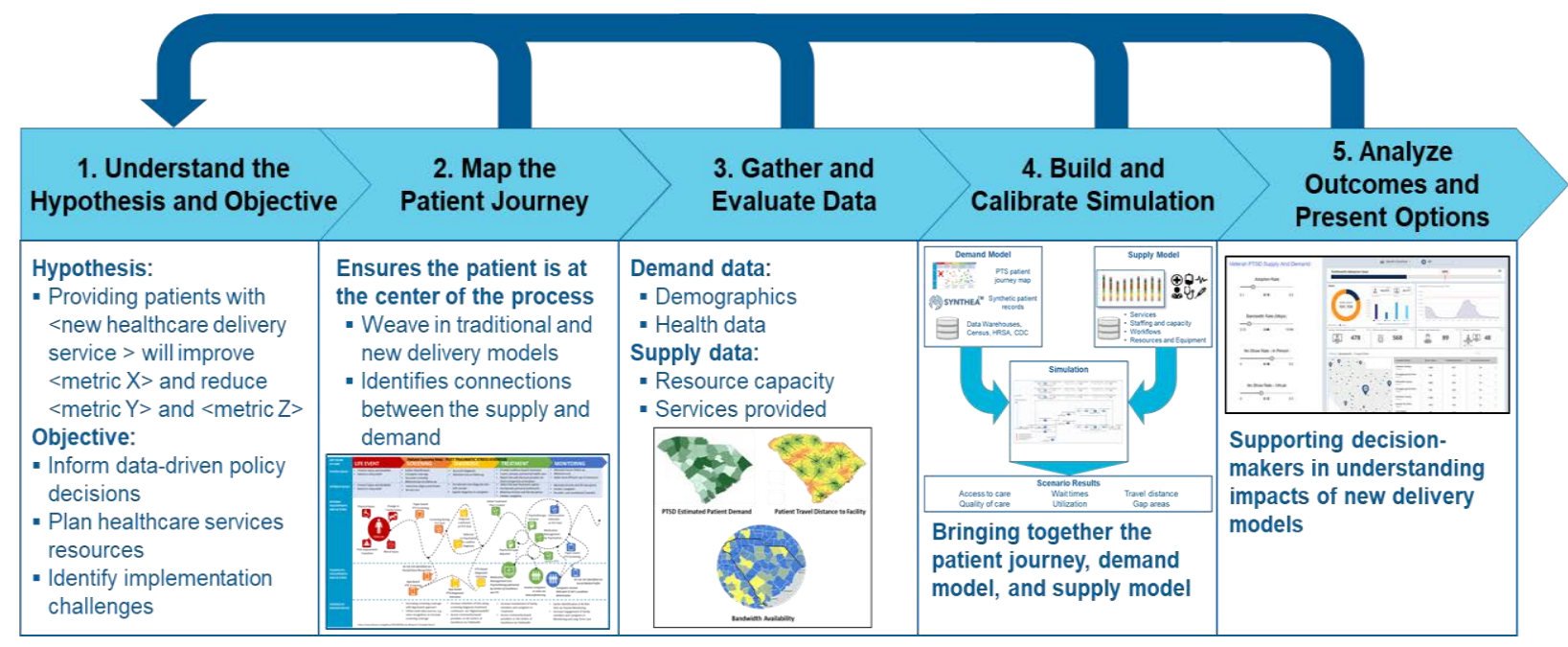

Figure 1: Modeling HealthCARE framework.

\subsection{Understanding the Hypothesis and Objective}

This step involves defining the hypothesis and objectives for the new healthcare delivery service. It should demonstrate how the hypothesis and objective can be shaped for a specific condition or treatment and the new healthcare delivery option being considered by the healthcare organization. The hypothesis should be defined as follows:

- Providing patients with $<$ new healthcare delivery service $>$ will improve $<$ metric $\mathrm{X}>$ and reduce $<$ metric $\mathrm{Y}>$ and $<$ metric $\mathrm{Z}>$. 
And the objective should be defined by examining the following questions:

- How might this inform data-driven policy decisions?

- How do we have to plan healthcare service resources?

- What are potential implementation challenges?

Use Case Telehealth for PTSD Treatment: The hypothesis is: providing patients with increased telehealth options for PTSD treatment will improve access by reducing patient wait times and travel distances. The objectives are:

- What will be the demand for trained providers and telehealth access points?

- What will be the effect on wait times?

- What will be savings for time spent traveling and travel distance?

\subsection{Map the Patient Journey}

This step focuses on putting the patient at the center of the process as traditional and new delivery models are weaved together and helps to identify the connections between supply and demand. It also looks at the goals of the healthcare organization and patient that can be considered in evaluating potential changes to understand the impacts they will have on both. Finally, it looks at the opportunities the new healthcare delivery option will bring to the patients in improving their experience and outcomes. The patient journey map is a critical piece to the framework as it provides the foundation of the modeling and simulation environment, as well as a common understanding of the current and future state of healthcare delivery. The journey map provides the foundation in understanding the patient-centric view of their touchpoints with the healthcare system, along with the demand for care the healthcare system must meet.

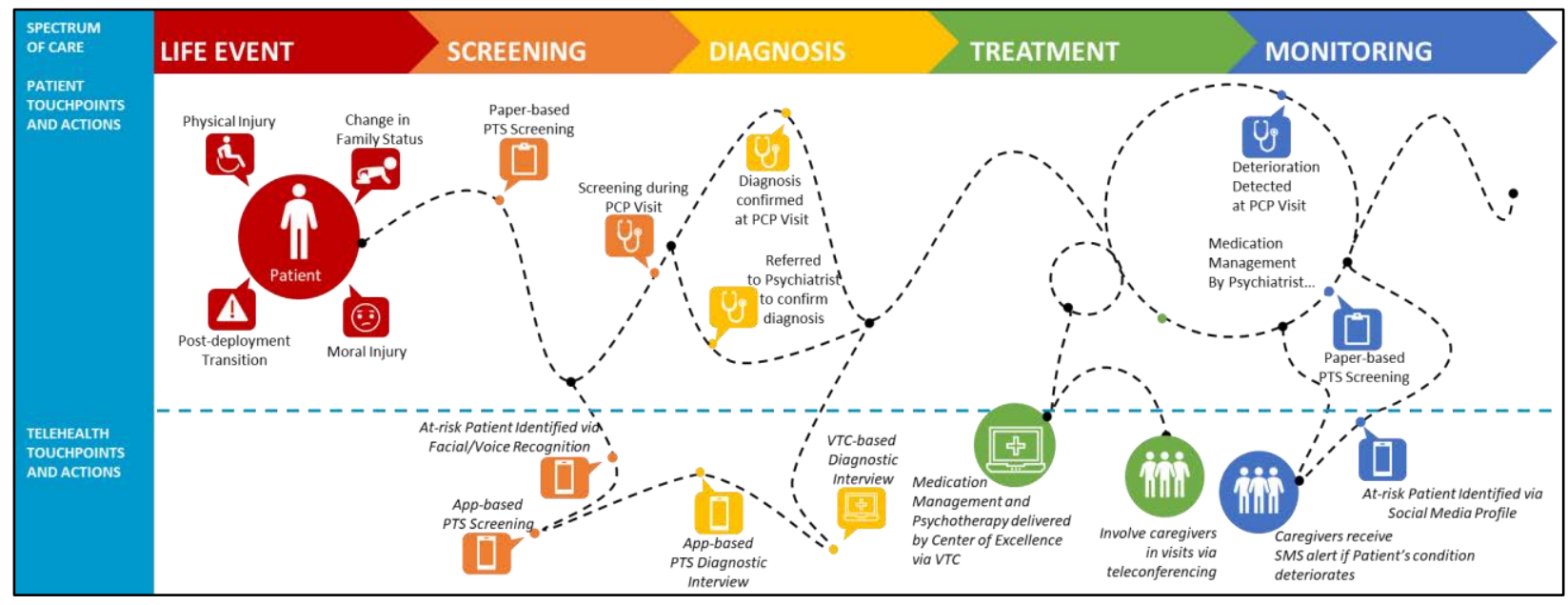

Figure 2: Patient Journey Map for PTSD.

Use Case Telehealth for PTSD Treatment: The journey map, shown in Figure 2, details a patient using traditional healthcare services in the large middle row, and the bottom row depicts how a patient might combine traditional services and virtual care. This provides the necessary insights into how a patient would move through and use healthcare services. It was developed in collaboration with VHA PTSD providers using a template created for a service blueprint (Wells 2016). The full journey map includes:

- Stages of the patient journey across the top along with the system patient goals;

- Patient's encounters with the healthcare system, showing how telehealth could be weaved into the traditional patient journey; and

- Benefits that telehealth would create for the patient and system (not shown in image for brevity). 


\subsection{Gather and Evaluate Data}

Relevant data is identified, gathered, and analyzed that supports the hypothesis and objective, and is aligned to the patient journey map to support evaluation of the proposed healthcare delivery changes. This data includes, for example, demographics, patient health records, available resources, and services provided.

Use Case Telehealth for PTSD Treatment: Because this is an independent research effort, we use several publicly available data sources to understand and model the demand for PTSD treatment from Veteran patients. First, VA's National Center for PTSD provides insights into how common PTSD is in Veterans by identifying prevalence rates based on service era (U.S. Dept. of Veterans Affairs 2018a). In addition, the 2013-2017 American Community Survey (ACS) 5-year estimates provides the number of Veterans by county in South Carolina. The columns from the Veteran's status portion (S2101) were (U.S. Census Bureau 2017). These two data sources combined lead to the assumptions in Table 1.

Table 1: Assumptions about PTSD prevalence.

\begin{tabular}{lcll} 
Veteran Population & $\begin{array}{c}\text { Column } \\
\text { in S2101 }\end{array}$ & $\begin{array}{c}\text { Percentage } \\
\text { Assumed }\end{array}$ & Further explanation \\
\hline $\begin{array}{l}\text { Operations Iraqi Freedom and } \\
\text { Enduring Freedom }\end{array}$ & $\mathrm{A}$ & $15.5 \%$ & Average between $11 \%$ and $20 \%$ \\
\hline Gulf War & $\mathrm{B}$ & $12 \%$ & \\
\hline Vietnam War & $\mathrm{C}$ & $15 \%$ & late 1980s study (30\% in lifetime) \\
\hline Korean War & $\mathrm{D}$ & $15 \%$ & \\
\hline WWII & $\mathrm{E}$ & $15 \%$ & \\
\hline
\end{tabular}

It is important to note that VA's Veteran Population Project Modeling 2016 (VetPop2016) model estimates a total of 403,948 Veterans in South Carolina across all service eras (U.S. Dept. of Veterans Affairs 2017a). However, the total from the 2013-2017 ACS 5-year estimate total across all services eras is 331,149 Veterans in South Carolina. Both sources have some margin of error associated with the estimates, however, the ACS data provides a breakdown by both service area and county, allowing application of the assumed prevalence rates at the county level. Until more detailed data is available from VA, the ACS data is sufficient to demonstrate the capabilities of the M\&S environment.

The M\&S environment is currently focused on the PTSD services that the Veteran Health Administration (VHA) provides in VA Medical Centers (VAMC) and Community-Based Outpatient Clinics (CBOCs). While the estimated Veterans with PTSD is 47,546, not all of those Veterans will use VHA's services. To adjust the estimate, VA's FY19 budget for Medical Programs provides the actual number of unique Veterans enrolled in VA healthcare benefits at 9.1M in FY17 (U.S. Dept. of Veterans Affairs 2018b). Based on the VetPop2016 model, in FY17 there was an estimated 20.3M Veterans, equating to a Veteran enrollee rate of $45 \%$. This assumption of $45 \%$ is applied to the 47,546 estimated Veterans with PTSD in South Carolina, bringing the total to 21,396 estimated Veterans with PTSD that could potentially receive services from VHA.

Figure 3 (left) shows the estimated VHA PTSD patients by county based on this analysis. Figure 3 (right) provides the results of a service area mapping for each of the VAMCs and CBOCs, along with lines showing the closest VHA facility to each county's population centroid. This information is used in the simulation model described in the following section. 

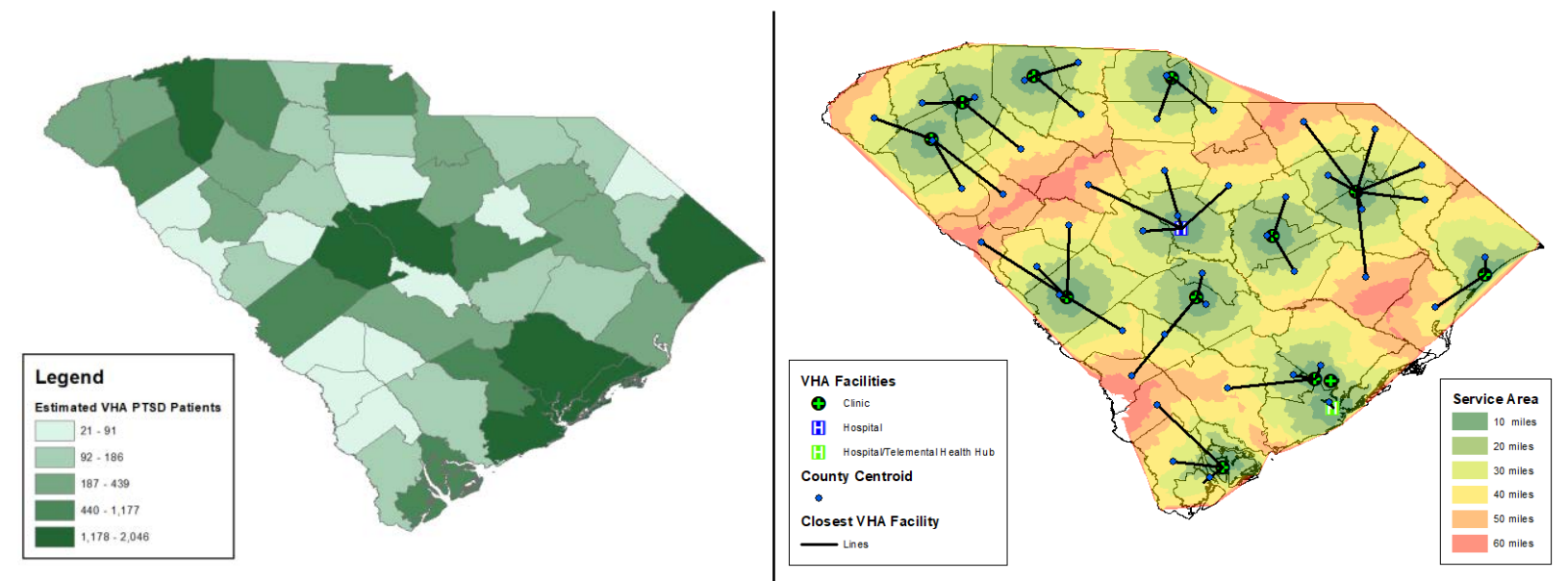

Figure 3: (left) Estimated VHA PTSD patients by county; (right) Service area and closet VHA facility.

Publicly available data from VA's monthly audits provide data on the number of mental health appointments and wait times (U.S. Dept. of Veterans Affairs 2017-2018). At the time of the analysis, data was gathered over a nine month period from October 2017 to June 2018 and is summarized with average number of appointments per month and average wait time in days in Table 2. This data is used as the basis for the assumptions around appointment capacities at the medical centers and clinics in South Carolina.

Table 2: Appointments and wait times in South Carolina.

\begin{tabular}{lll} 
Facility & Avg. Mental Health App. Per Month & Avg. Wait Time in Days \\
\hline Medical Center A & 24,528 & 2.0 \\
\hline Medical Center B & 35,684 & 4.0 \\
\hline Clinic A & 1,225 & 1.3 \\
\hline Clinic B & 3,468 & 5.8 \\
\hline Clinic C & 2,343 & 2.1 \\
\hline Clinic D & 5,133 & 3.7 \\
\hline Clinic E & 2,836 & 2.6 \\
\hline Clinic F & 6,421 & 9.0 \\
\hline Clinic G & 2,075 & 1.7 \\
\hline Clinic H & 2,697 & 1.5 \\
\hline Clinic I & 2,661 & 4.1 \\
\hline Clinic J & 1,045 & 4.1 \\
\hline Clinic K & 1,505 & 2.9 \\
\hline Clinic L & 1,761 & 3.0
\end{tabular}

\subsection{Build and Calibrate Simulation}

The M\&S environment brings together the patient journey map, demand model, and supply model. Encoding the patient journey into a hybrid simulation model includes a bottom-up, agent-based approach to model patient behaviors and decisions and a traditional top-down, discrete-event approach to model healthcare system processes, set high-level parameters, and understand impacts to performance measures.

Use Case Telehealth for PTSD Treatment: We start by encoding the patient journey into a hybrid simulation model. We model the patients as agents based on county-level Veteran population data, PTSD 
prevalence rates, and VA enrollee rates. Facility capacities are then calculated based on public data from VA showing the number of completed appointments and wait times. Finally, telehealth adoption rates and no-show rates are modeled to reflect patient behaviors as they receive treatments.

The M\&S environment is implemented in AnyLogic where agents are created to represent both the patients as well as the supply capacity. The patients are generated at the beginning of the simulation. When each patient is generated, the following patient attributes are initialized:

- County name, latitude and longitude

- Number of patients

- Closest medical center for in-person appointments, latitude, longitude, and distance

- Closet clinic or medical center for virtual appointments, latitude, longitude, and distance

- Treatment delivery preference

- Number of treatments completed

- Latest appointment request date

- Latest appointment date

- Total distance traveled

Figure 4 shows the process modeled within AnyLogic that represents the treatment portion of the patient journey map. Not shown in this figure is the generation, consumption, and removal virtual care delivery appointments, virtual care access appointments, and in-person delivery appointments. The delivery appointments are the appointments with the actual provider, while the virtual care access appointments are appointments for the rooms available to patient at the clinic or medical center where they can connect via video to their provider in a different location. When making an appointment for virtual delivery, the system must make both a virtual access appointment and virtual delivery appointment that take place at the same day and time. The appointments are sent to two different sets of 'sinks' in the model (i.e., removed from the simulation) as they are used, or as their date and time passes in the simulation and they are still unused.

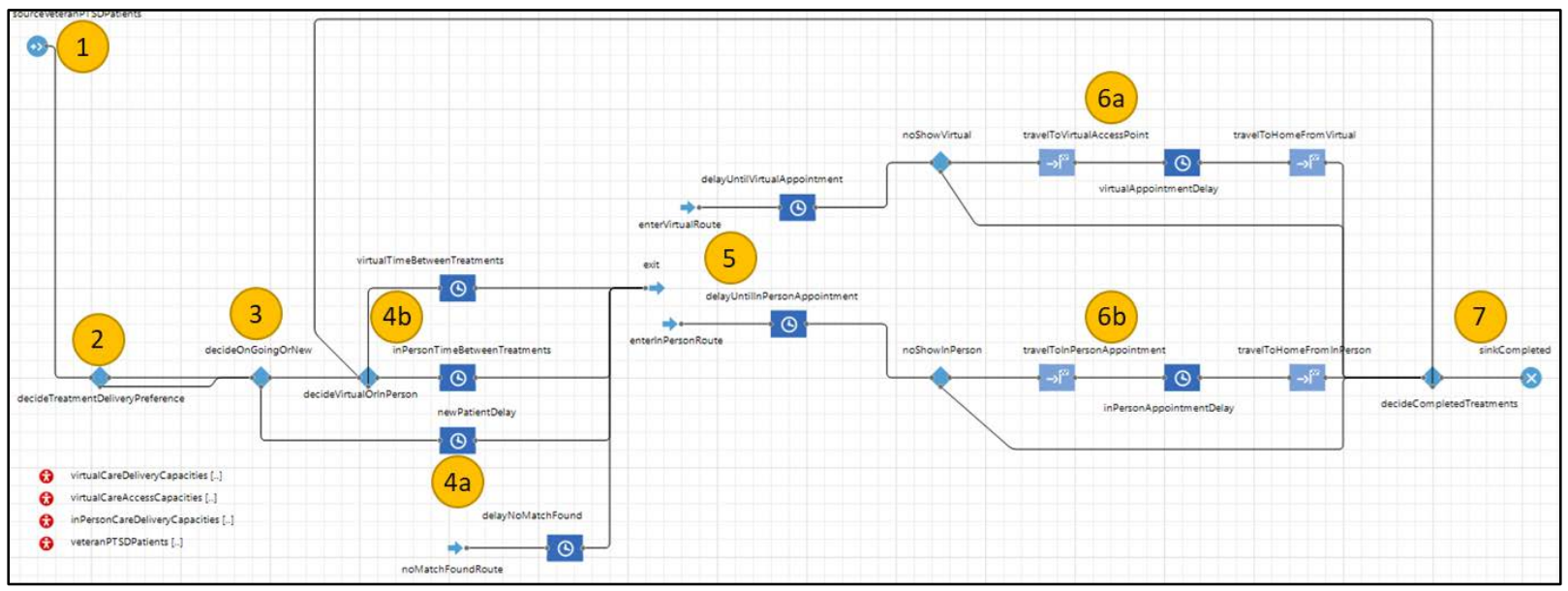

Figure 4: M\&S environment: in-person and virtual treatments for PTSD patients.

Table 3 provides a description of what happens at each step within the M\&S environment for this use case.

Table 3: Description of M\&S environment for PTSD treatments.

\begin{tabular}{|l|l|}
\hline Step & Description \\
\hline $\begin{array}{l}\text { 1. Generate Veteran PTSD } \\
\text { patients by county }\end{array}$ & $\begin{array}{l}\text { This generates the individual patients based on the estimates by county, and } \\
\text { sets the parameters including their home county, closest medical center for } \\
\text { in-person appointments, and closest clinic or medical center for virtual. }\end{array}$ \\
\hline
\end{tabular}




\begin{tabular}{|c|c|}
\hline Step & Description \\
\hline $\begin{array}{l}\text { 2. Set delivery treatment } \\
\text { preference }\end{array}$ & $\begin{array}{l}\text { The percentage of patients assumed to prefer virtual appointments is input } \\
\text { at the beginning of the simulation. Based on that percentage, this sets } \\
\text { whether patients prefer virtual or in-person appointments. }\end{array}$ \\
\hline $\begin{array}{l}\text { 3. Determine if this is a } \\
\text { new patient or if they have } \\
\text { an ongoing care plan }\end{array}$ & $\begin{array}{l}\text { Based on a percentage, this sets whether the patients are new patients to the } \\
\text { system, or if they already have an ongoing care plan and have completed } \\
\text { some of their treatments. }\end{array}$ \\
\hline 4a. New patient delay & $\begin{array}{l}\text { If the patient was new, this module delays the patients' arrival into the } \\
\text { treatment process. Note: this is done because all patients are generated at } \\
\text { the beginning of the simulation, however, all patients do not begin } \\
\text { treatment at the same time in the beginning of the year. }\end{array}$ \\
\hline $\begin{array}{l}\text { 4b. Existing patients - } \\
\text { virtual or in-person } \\
\text { appointment process }\end{array}$ & $\begin{array}{l}\text { If the patient was an existing patient, or is going to make their next } \\
\text { appointment, first the model looks at their treatment preferences and sends } \\
\text { them to one of two modules: 1) a delay between treatments for virtual } \\
\text { appointments; or 2) a delay between treatments for in-person appointments. }\end{array}$ \\
\hline 5. Appointment selection & $\begin{array}{l}\text { These set of modules evaluate the next appointment available for both in- } \\
\text { person and virtual appointments. } \\
\text { - If the earliest of the two appointment types matches their preference, } \\
\text { the patient is assigned that appointment date and time. } \\
\text { - If the earliest of the two appointment types does not match their } \\
\text { preference, they have the ability to go against their preference and } \\
\text { select the other appointment type. This includes a threshold level for } \\
\text { how many days sooner the other appointment must be in order for } \\
\text { them to go against their initial preference. } \\
\text { - If no appointments are available, they wait for a specified amount of } \\
\text { time and then try again. } \\
\text { Once the appointment is selected, it sends them on the appropriate route, } \\
\text { virtual or in-person. Then they wait until their appointment date and time. }\end{array}$ \\
\hline $\begin{array}{l}\text { 6a. Virtual treatment } \\
\text { appointment }\end{array}$ & $\begin{array}{l}\text { For the virtual appointments: } \\
\text { 1) First, on the day of the appointment based on a percentage, there is a } \\
\text { chance the patient will decide not to show up to their virtual appoint- } \\
\text { ment. If so, they go back to step } 4 \text { b. } \\
\text { 2) If they are going to their appointment, the patient travels to the closest } \\
\text { clinic or medical center to have their virtual access appointment. } \\
\text { 3) They receive their treatment virtually. } \\
\text { 4) They travel back to their home county }\end{array}$ \\
\hline $\begin{array}{l}\text { 6b. In-person treatment } \\
\text { appointment }\end{array}$ & $\begin{array}{l}\text { For the in-person appointments: } \\
\text { 1) First, on the day of the appointment based on a percentage, there is a } \\
\text { chance the patient will decide not to show up to their in-person ap- } \\
\text { pointment. If so, they go back to step } 4 \mathrm{~b} \text {. } \\
\text { 2) If they are going to their appointment, the patient travels to their speci- } \\
\text { fied closest medical center to have their in-person appointment. } \\
\text { 3) They receive their treatment in-person. } \\
\text { 4) They travel back to their home county }\end{array}$ \\
\hline $\begin{array}{l}\text { 7. Completion of care plan } \\
\text { and exit }\end{array}$ & $\begin{array}{l}\text { If the patient still has remaining treatments in their care plan, they go back } \\
\text { to step } 4 \mathrm{~b} \text {. Otherwise, they are sent to a 'sink' module that removes them } \\
\text { from the simulation. }\end{array}$ \\
\hline
\end{tabular}

This research is based on publicly available and synthetic data, and we make certain assumptions about the patients that are detailed in Table 4. 
Table 4: Assumptions used in M\&S.

\section{Numerical Assumption Description}

$18 \%$ of in-person patients Will not show up on the day of their appointment (Institute of Medicine 2014) Will not show up on the day of their appointment (assumed to be less than in-

$12 \%$ of virtual patients person based on prior telepsychology research (Leigh, Cruz and Mallios 2009), however, more data is needed from VHA to improve this assumption)

10 days Patient will switch their preferred appointment type if it is available with this threshold

The number of appointments in a care plan (U.S. Dept. of Veterans Affairs

12 appointments 2017b)

\begin{tabular}{ll}
\hline $25 \%$ patients & Will have on-going care plans at the start of the year \\
\hline $75 \%$ patients & Will have new care plans at the start of the year \\
\hline $\begin{array}{l}\text { Normal distribution } \\
\text { between } 1 \text { and } 11\end{array}$ & $\begin{array}{l}\text { For those patients with on-going care plans, number of appointments already } \\
\text { completed }\end{array}$ \\
\hline
\end{tabular}

Table 5 provides an additional set of assumptions used to model three scenarios, with scenario $a$ being the base case used to calibrate the model. We assume that all providers are divided between the two main medical centers in SC, and that the patients that elect to use telehealth will travel to their local clinic and have an appointment with those providers virtually.

Table 5: Capacity assumptions by scenarios.

\begin{tabular}{|c|c|c|c|c|}
\hline & $\begin{array}{c}\text { In-person } \\
\text { Provider } \\
\text { Appointments } \\
\text { Available Per Day }\end{array}$ & $\begin{array}{c}\text { Virtual Provider } \\
\text { Appointments } \\
\text { Available Per } \\
\text { Day }\end{array}$ & \multicolumn{2}{|c|}{$\begin{array}{l}\text { Patient Virtual Rooms } \\
\text { Appointments Per Day }\end{array}$} \\
\hline Facility & Scenario a, & , b and $c$ & Scenario a and $b$ & Scenario c \\
\hline Medical Center A & 222 & 39 & 26 & 28 \\
\hline Medical Center B & 322 & 57 & 36 & 36 \\
\hline Clinic A & 0 & 0 & 2 & 4 \\
\hline Clinic B & 0 & 0 & 4 & 4 \\
\hline Clinic $\mathrm{C}$ & 0 & 0 & 3 & 4 \\
\hline Clinic D & 0 & 0 & 6 & 8 \\
\hline Clinic E & 0 & 0 & 3 & 4 \\
\hline Clinic F & 0 & 0 & 7 & 8 \\
\hline Clinic $\mathrm{G}$ & 0 & 0 & 3 & 4 \\
\hline Clinic $\mathrm{H}$ & 0 & 0 & 3 & 4 \\
\hline Clinic I & 0 & 0 & 3 & 4 \\
\hline Clinic $\mathrm{J}$ & 0 & 0 & 2 & 4 \\
\hline Clinic K & 0 & 0 & 2 & 4 \\
\hline Clinic L & 0 & 0 & 2 & 4 \\
\hline
\end{tabular}

We calibrate the capacity settings to achieve an average wait time consistent with those in Table 2 (approximately 3 days). Actual capacity data for PTSD treatments is not available publicly, however, we 
do have access to higher level data on appointment completions per day for all appointments. In the future, this calibration step will focus on the other assumptions as we gain access to real-world data.

\subsection{Analyze Outcomes and Present Options}

This final step in the framework addresses the hypothesis and objective by answering questions about the healthcare organization's performance and, more importantly, the patients' experiences and outcomes. Visualizing the results of the simulation allows decision-makers to better understand the impacts of the options they are considering.

Use Case Telehealth for PTSD Treatment: With this use case, we seek to answer the questions: Will the average wait time and travel distances for patients decrease? Will patient access to care increase? Are there enough resources to meet demand?

Table 6 provides an overview of the results from each of the scenario simulations. We ran each scenario simulation once as the model is still a proof of concept and more data is needed to further calibrate the model and provide statistically significant results. The scenarios are:

a. Assume a telehealth adoption rate of $15 \%$, and the base capacity settings in Table 5

b. Assume a telehealth adoption rate of $25 \%$, and the base capacity settings in Table 5

c. Assume a telehealth adoption rate of $25 \%$, and the increased capacity settings in Table 5

We ran the model for one year, with the first six months acting as a warmup period and evaluate results over a 90-day period from the end of that warmup period. Based on the results, it appears that this model can be used to evaluate different healthcare delivery options and capacity scenarios to allow decisionmakers to understand the potential impacts on patients. In scenario $a$, we see the average wait time for inperson appointments is close to the average three day wait time used for calibration. As we increase adoption of telehealth in scenario $b$, wait times begin to decrease, and then further increasing capacity of the virtual rooms in scenario $c$ brings wait times down even more.

Table 6: Results of scenarios: wait time and travel distance.

\begin{tabular}{ccccc} 
Scenario & $\begin{array}{c}\text { Average In-Person } \\
\text { Wait Time (Days) }\end{array}$ & $\begin{array}{c}\text { Average Virtual } \\
\text { Wait Time (Days) }\end{array}$ & $\begin{array}{c}\text { Average Wait Time } \\
\text { (Days) }\end{array}$ & $\begin{array}{c}\text { Average Travel } \\
\text { Distance (Miles) }\end{array}$ \\
\hline a. & 2.92 & 0.58 & 2.70 & 110.55 \\
\hline b. & 2.36 & 0.63 & 2.15 & 110.19 \\
\hline c. & 1.81 & 0.61 & 1.64 & 107.59 \\
\hline
\end{tabular}

We ran an additional scenario where the virtual room capacity for the two medical centers is set to zero, and all others are increased by four appointments per day. Although the resulting increase in wait times is minimal, the average travel distance decreases to about 101 miles, or a savings of about 381 thousand miles in a 90-day period across all patients. This demonstrates the potential to use simulation to evaluate the tradeoffs for implementing services and capacities in different locations and understanding the impacts to both wait time and travel distances.

\section{CONCLUSIONS AND FUTURE WORK}

The hybrid simulation model uses a bottom-up, agent-based approach to model patient behaviors and decisions, and a traditional top-down, discrete-event approach to model healthcare system processes, set high-level parameters, and understand impacts to performance measures. With this novel approach, we can replace assumptions about behavior with observed societal behavior, to include social determinates which influence adoption of new healthcare services, and we hope to show improved credibility of model results. 
A limitation of our research is access to real-world data from healthcare systems that could provide more detailed insights into supply, demand, and patient behaviors. Initial results using publicly available data indicate decreased average wait times and travel distances as telehealth adoption increases, with further decreases possible as telehealth capacity is increased. Results also indicate the potential clinician and equipment requirements at each of the locations. Based on these outcomes, we believe incorporation of additional data sources will help to improve the accuracy of the model and enable VA to make data-driven decisions as it continues to implement PTSD telehealth care.

Furthermore, this framework can be applied to many use cases, including other healthcare organizations and new healthcare delivery services beyond telehealth. It can be extended to answer key questions around both provider and patient experiences, such as other healthcare conditions, clinician and patient burnout, and impacts of social determinants of health. We are looking to partner with organizations to develop additional use cases and validate our data and models based on real world experience.

\section{REFERENCES}

Alibrahim, Abdullah, and Shinyi Wu. 2018. "An agent-based simulation model of patient choice of health care providers in accountable care organizations." Health Care Management Science 21 (1): 131143.

Brailsford, Sally C., Tillal Eldabi, Martin Kunc, Navonil Mustafee, and Andres F. Osorio. 2019. "Hybrid simulation modelling in operational research: A state-of-the-art review." European Journal of Operational Research 278: 721-737.

Craven, Teri J., and Carolina C. Krejci. 2017. "An Agent-Based Model of Regional Food Supply Chain Disintermediation." SpringSim-ADS. Virginia Beach, VA, USA: Society for Modeling \& Simulation International (SCS).

Easter, Benjamin, Negin Houshiarian, Debajyoti Pati, and Jennifer L. Wiler. 2019. "Designing efficient emergency departments: Discrete event simulation of internal-waiting areas and split flow sorting." The American Journal of Emergency Medicine Available from: https://doi.org/10.1016/j.ajem.2019.03.017.

Institute of Medicine. Committee on the Assessment of Ongoing Efforts in the Treatment of Posttraumatic Stress Disorder. Board on the Health of Select Population. 2014. "8, Access to Care." Treatment for Posttraumatic Stress Disorder in Military and Veteran Populations: Final Assessment. June 17. https://www.ncbi.nlm.nih.gov/books/NBK224888/.

Leigh, Hoyle, Herbert Cruz, and Ronna Mallios. 2009. "Telepsychiatry appointments in a continuing care setting: kept, cancelled and no-shows." Journal of Telemedicine and Telecare 286-289.

Musdal, Hande, Brian Shiner, Techieh Chen, Mehmet Ceyhan, Bradley Watts, and James Benneyan. 2014. "In-Person and Video-Based Post-Traumatic Stress Disorder Treatment for Veterans: A LocationAllocation Model." Military Medicine 179 (2): 150-156.

Roth, Mandy. 2018. "4 Insights To Build A Better Command Center." HealthLeaders, June 7: Available from: https://www.healthleadersmedia.com/innovation/4-insights-build-better-command-center.

Saoud, Manel Saad, Abdelhak Boubetra, and Safa Attia. 2018. "A Simulation Decision Support System for the Healthcare Emergency Department Optimization." In Handbook of Research on Emerging Perspectives on Healthcare Information Systems and Informatics, 347-367. Hershey, PA: IGI Global.

Sbayou, Mariem, Youssef Bouanan, Gregory Zacharewicz, Judicael Ribault, and Julien Francois. 2017. "DEVS Modelling and Simulation for Healthcare Process Application for Hospital Emergency Department." SpringSim-ANSS. Virginia Beach, VA, USA: Society for Modeling \& Simulation International (SCS). 
Sian Morgan, Jennifer, and Anna Graber-Naidich. 2019. "Small system dynamics model for alleviating the general practitioners rural care gap in Ontario, Canada." Socio-Economic Planning Sciences 66: $10-23$.

The MITRE Corporation. 2017. Synthea. https://synthea.mitre.org/about.

U.S. Census Bureau. 2017. "VETERAN STATUS 2013-2017 American Community Survey 5-Year Estimates [Table S2101]." American FactFinder. https://data.census.gov/cedsci/table?q=Veteran\%20Status\&g=0400000US45.050000\&hidePrevie $\mathrm{w}=$ true \& table $=$ S2101\&tid=ACSST5Y2017.S2101\&lastDisplayedRow $=48$.

U.S. Dept. of Veterans Affairs. 2018b. "Annual Budget Submission [FY 2019 Budget Submission - Volume II, pg. 45]." Office of Budget. February 12. https://www.va.gov/budget/products.asp.

-.2018a. How Common is PTSD in Veterans? September 24. https://www.ptsd.va.gov/understand/common/common_veterans.asp.

—. 2017-2018. "Patient Access Data." Veterans Health Administration. https://www.va.gov/health/accessaudit.asp.

- 2017b. "Treatment Comparison Chart." PTSD Decision Aid. June. https://www.ptsd.va.gov/apps/decisionaid/compare.aspx.

—. 2019. VA Telehealth Services. November 20. https://telehealth.va.gov/.

—. 2017a. "Veteran Population [Table 9L - County]." National Center for Veterans Analysis and Statistics. June. https://www.va.gov/vetdata/Veteran_Population.asp.

Wells, Gordon. 2016. Service Blueprint Template + Stencil. February 29. https://www.behance.net/gallery/34532659/Service-Blueprint-Template-Stencil.

\section{AUTHOR BIOGRAPHIES}

MATTHEW HENCHEY is a member of The MITRE Corporation's Operations Research Department and serves as a lead operations research analyst. He provides optimization, modeling, and simulation expertise for several of MITRE's government sponsors, developing solutions to support data-driven decision making. This includes using simulation to evaluate new healthcare delivery models, the focus of this presentation. He holds a PhD in Operations Research from the University at Buffalo. His email address is mhenchey@mitre.org.

DEBORAH ERCOLINI is a member of The MITRE Corporation's Collaboration and Social Computing Department and serves as a Software and Systems Engineer, a Human Factors and User Experience Engineer, an Accessibility Engineer, and a Resource Manager. She has 30 years of experience working as a software designer, architect and developer with a recent focus on enhancing the user experience of different systems. She has been a project manager of many large software and systems development and deployment efforts, including research proposal development and execution. Ms. Ercolini has a B.S. in Computer Science and Engineering, M.S. in Information Systems, and M.S. in Human Factors in Information Design. Her email address is deb@mitre.org.

SYBIL KLAUS is a chief scientist and The MITRE Corporation's health innovation area portfolio leader. She is a board-certified pediatrician with a joint appointment as a pediatric hospitalist at Johns Hopkins University School of Medicine and Kennedy Krieger Institute. As a pediatrician and public health professional, Dr. Klaus has broad experience as a researcher, physician, and public health expert. Dr. Klaus has led or contributed to numerous health-related research projects and served as a mentor for medical students, residents, and early career researchers. Dr. Klaus earned a B.A. in political science and a B.S. in cell and molecular biology from Tulane University, an M.D. from Emory University School of Medicine, residency at University of California San Diego, and an M.P.H. from Johns Hopkins Bloomberg School of Public Health with a certification in quality and safety, as well as clinical research. Her email address is sklaus@mitre.org. 